\title{
A NOTE ON THE CARRIER DETECTION OF HEMOPHILIA A
}

\author{
Akira Yoshioka,*' Yoshihiro FuJImura, and \\ Keiichiro YosHIOKA \\ Department of Pediatrics, National \\ Osaka Hospital, Osaka, Japan
}

\begin{abstract}
Summary We have examined the problem of identifying carriers of hemophilia A by using three comparative studies: the human AHF-inhibitorneutralization test, the rabbit anti-human AHF antiserum-neutralization test, and quantitative immunoelectrophoresis. Twelve out of $22(54.5 \%)$ definite carriers could be distinguished on the basis of their VIII : $\mathrm{C}$ alone; 19 out of $22(86 \%)$ could be detected on the basis of the ratio of VIII : C to VIII : AG at the $99 \%$ confidence limit, and 20 out of $22(91 \%)$ could be detected if both were taken into account. It is concluded that consideration of the level of VIII : $\mathrm{C}$ as well as the ratio of VIII : $\mathrm{C}$ to VIII : AG is the most reliable means of detecting the carrier state. Application of this method to 16 probable and 14 potential carriers identified the carrier state in 11 and 9 , respectively.
\end{abstract}

\section{INTRODUCTION}

Hemophilia $\mathrm{A}$ is a prototype of an $\mathrm{X}$-chromosome linked recessive trait characterized by decreased plasma factor VIII (procoagulant activity of antihemophilic factor VIII:C) levels as measured by specific clotting assays. Ordinarily, the hemorrhagic tendency of this disorder is manifest only in males. Female carriers of the abnormal gene are usually asymptomatic. Detection of carriers of hemophilia A remains a difficult and still controversial problem. Hitherto, detection of the carrier state has depended upon the measurement of VIII:C. It has been shown that carriers of hemophilia A have on average a lower plasma level of VIII:C than normal women. But the wide range of overlapping values makes it possible to identify only about a half of the carriers by this means (Rapaport et al., 1960; Ikari, 1969).

Recent studies by the antibody-neutralization method have demonstrated that in some patients with hemophilia A, an immunological cross-reacting material (VIII:CRM) can be detected, while in others it cannot (Denson et al., 1969). Other recent studies have shown the presence of normal or increased amounts of an

*Present Address: Department of Pediatrics, Nara Medical University, Kashihara, Japan. Received March 11, 1977 
inactive protein, antigenically similar to normal factor VIII, in the plasma of all hemophilia A patients tested. This antigenic material is called "factor VIII-like antigen" (VIII:AG) (Zimmerman et al., 1971).

The present paper is concerned with an approach to the carrier detection of hemophilia A using two immunological assay methods, namely, the inhibitor- or antibody-neutralization method and immunoelectrophoresis.

\section{MATERIALS AND METHODS}

Fifty two women belonging to families with a history of hemophilia and registered at National Osaka Hospital were studied. Table 1 shows the three groups of carriers investigated. The term "definite carrier" was used to designate the daughter of an individual with hemophilia, the mother of more than one hemophiliac, or the mother of one hemophiliac when she had other hemophilic relatives. The term "probable carrier" described those women who had only one affected son and no other known affected relatives. The term "potential carrier" described daughters, sisters, or mothers of definite or probable carriers (Mersky and Macfarlane, 1951; Rapaport et al., 1960). According to the criteria mentioned above, in the present study, 22 of the women investigated were regarded as definite, 16 as probable and 14 as potential carriers. None of the women had a history of hemorrhagic symptoms or were known to be pregnant. The control group comprised 25 non-pregnant females and laboratory and hospital personnel with no familial or personal bleeding tendencies.

1) Factor VIII procoagulant assay. Anticoagulation was carried out with one part $0.1 \mathrm{~m}$ sodium oxalate to nine parts blood. Platelet-poor plasma (PPP) was prepared by centrifugation at $3000 \mathrm{~g}$ for $15 \mathrm{~min}$ at $4^{\circ} \mathrm{C}$. The assay of VIII: C was done on fresh plasma within three hours after sampling with the one stage method (Hardisty and Macpherson, 1962). The rest of the plasma was stored in plastic containers at $-70^{\circ} \mathrm{C}$ for no more than one month and used for two immunological assays based on the antibody-neutralization test and immuno-electrophoresis. All

Table 1. Investigated female persons in the families with hemophiliacs.

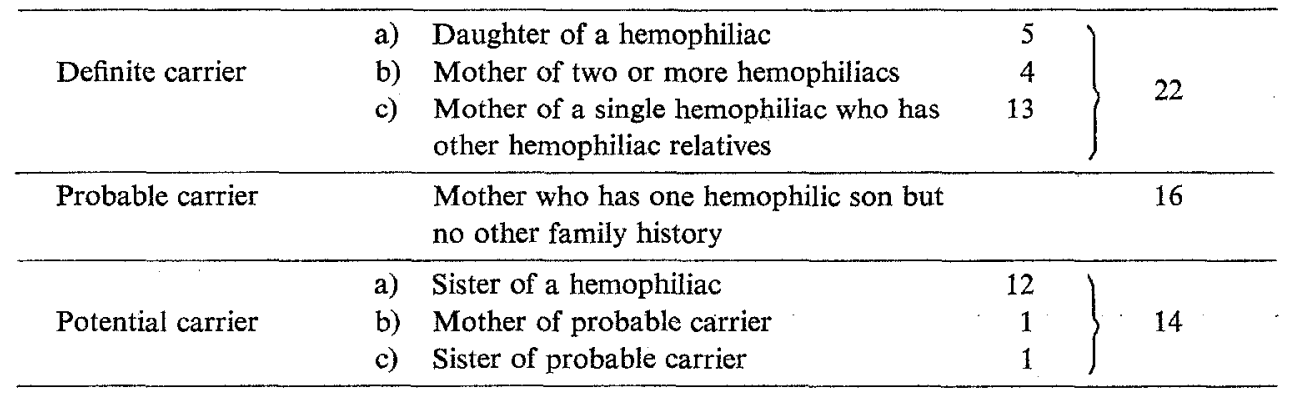


determinations were done in blind and duplicate. One unit of VIII: $\mathrm{C}$ is the amount present in $1 \mathrm{ml}$ of normal plasma.

2) Immunoassay. a) The amount of inhibitor-neutralization activity (VIII: $\mathrm{CRM}_{\mathrm{I}}$ ) was measured by inhibition of the anti-AHF activity of the human AHFinhibitor, developed in a severe case of hemophilia A, in test plasma.

b) The amount of antibody-neutralization activity (VIII:CRM $\mathrm{M}_{\mathrm{R}}$ ) was also measured by inhibition of the anti-AHF activity of the rabbit anti-human AHF antiserum in test plasma.

Excess AHF-inhibitior or rabbit anti-AHF antiserum was mixed with the test plasma and allowed to react with any cross-reacting material present. The residual amount of antibody was then measured using inhibitor assay (Bloom et al., 1966). The difference between the total and residual antibody was proportional to the amount of neutralization activity in the test plasma.

The immunoassay was performed by incubating $0.1 \mathrm{ml}(2 \mathrm{u} / \mathrm{ml})$ of inhibitor or antibody with $0.1 \mathrm{ml}$ of test plasma at $37^{\circ} \mathrm{C}$ for one hour and then at $4^{\circ} \mathrm{C}$ overnight. The precipitate was removed by centrifugation, $0.1 \mathrm{ml}$ of supernatant was then incubated with $0.4 \mathrm{ml}$ of normal PPP at $37^{\circ} \mathrm{C}$ for one hour, and residual VIII:C was assayed. With each batch of tests, the PPP was incubated with non-immunized rabbit serum at $37^{\circ} \mathrm{C}$ for one hour. Figure 1 shows the schema for neutralization of AHF-inhibitor or rabbit anti-AHF antiserum by test plasma. One unit of antibody-neutralization activity is the amount present in $1 \mathrm{ml}$ of normal pooled plasma. c) Quantitative immunoelectrophoresis of AHF was modified from the method of Laurell (1966). VIII:AG was assayed in 1\% agarose containing $0.3 \%$ of antiserum to human-AHF (Behringwerke's "anti-AHG"). Eight $\mu 1$ of each diluted plasma were placed in wells $3 \mathrm{~mm}$ in diameter, and a constant potential of $10 \mathrm{~V}$ per $\mathrm{cm}$ applied for three hours. All determinations were done in blind and duplicate. One unit of VIII:AG is the amount present in $1 \mathrm{ml}$ of normal pooled plasma.

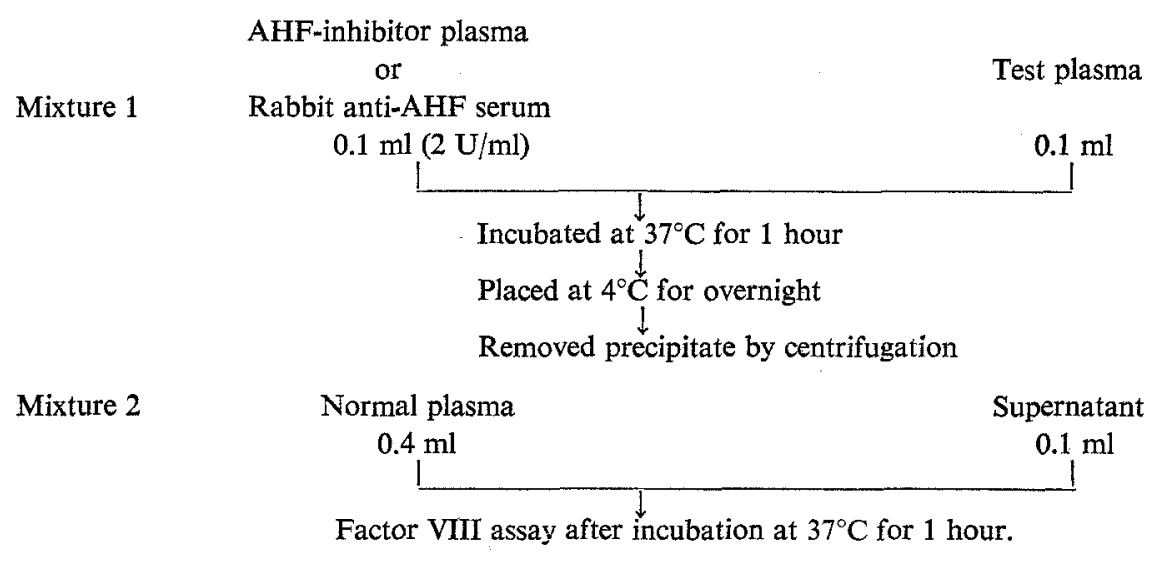

Fig. 1. Neutralization of AHF-inhibitor or rabbit anti-AHF antiserum by test plasma. 


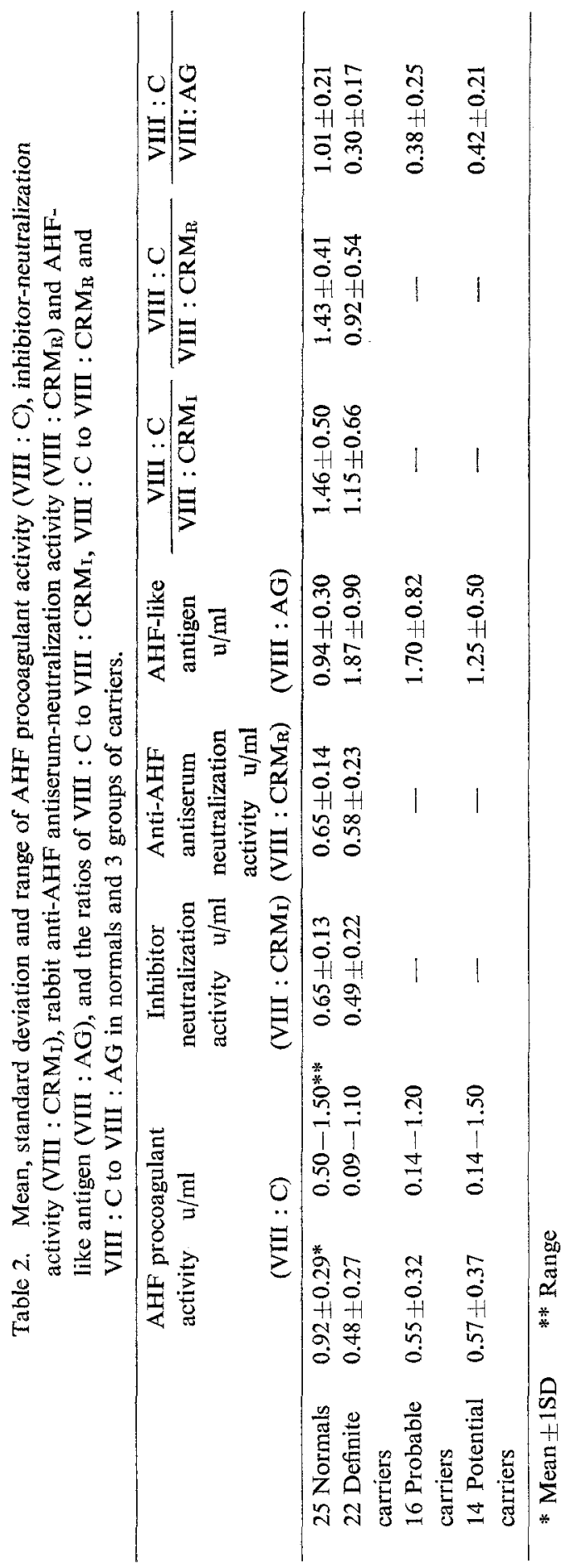




\section{RESULTS}

Table 2 shows the mean, standard deviation, and range of VIII:C, VIII:CRM VIII $: \mathrm{CRM}_{\mathrm{R}}$ and VIII:AG, and the ratios of VIII:C to VIII:CRM $\mathrm{C}_{\mathrm{I}}$ VIII:C to VIII: $\mathrm{CRM}_{\mathrm{R}}$ and VIII:C to VIII:AG in 25 normal individuals, 22 definite, 16 probable and 14 potential carriers. The geometric means of VIII:C in normal women and definite carriers were $1.00 \mathrm{u} / \mathrm{ml}$ and $0.48 \mathrm{u} / \mathrm{ml}$, respectively. The geometric mean of VIII:AG concentration by Laurell's method in normal women was $1.03 \mathrm{u} / \mathrm{ml}$, and that of carriers $1.87 \mathrm{u} / \mathrm{ml}$. The ratio of VIII:C to AHF-inhibitor-neutralization activity was $1.58 \pm$ 0.49 (mean $\pm 1 \mathrm{SD}$ ) in normal women and $1.15 \pm 0.66$ in definite carriers. The ratio of VIII:C to rabbit anti-human AHF antiserum-neutralization activity was $1.53 \pm$ 0.41 in normal women and $0.92 \pm 0.54$ in definite carriers. Both these values in definite carriers were less than in normal women, but they ranged widely and overlapped. On the other hand, the ratio of VIII:C to VIII:AG by Laurell's method (from now on called "specific ratio") was $1.00 \pm 0.21$ in normal women and $0.30 \pm$

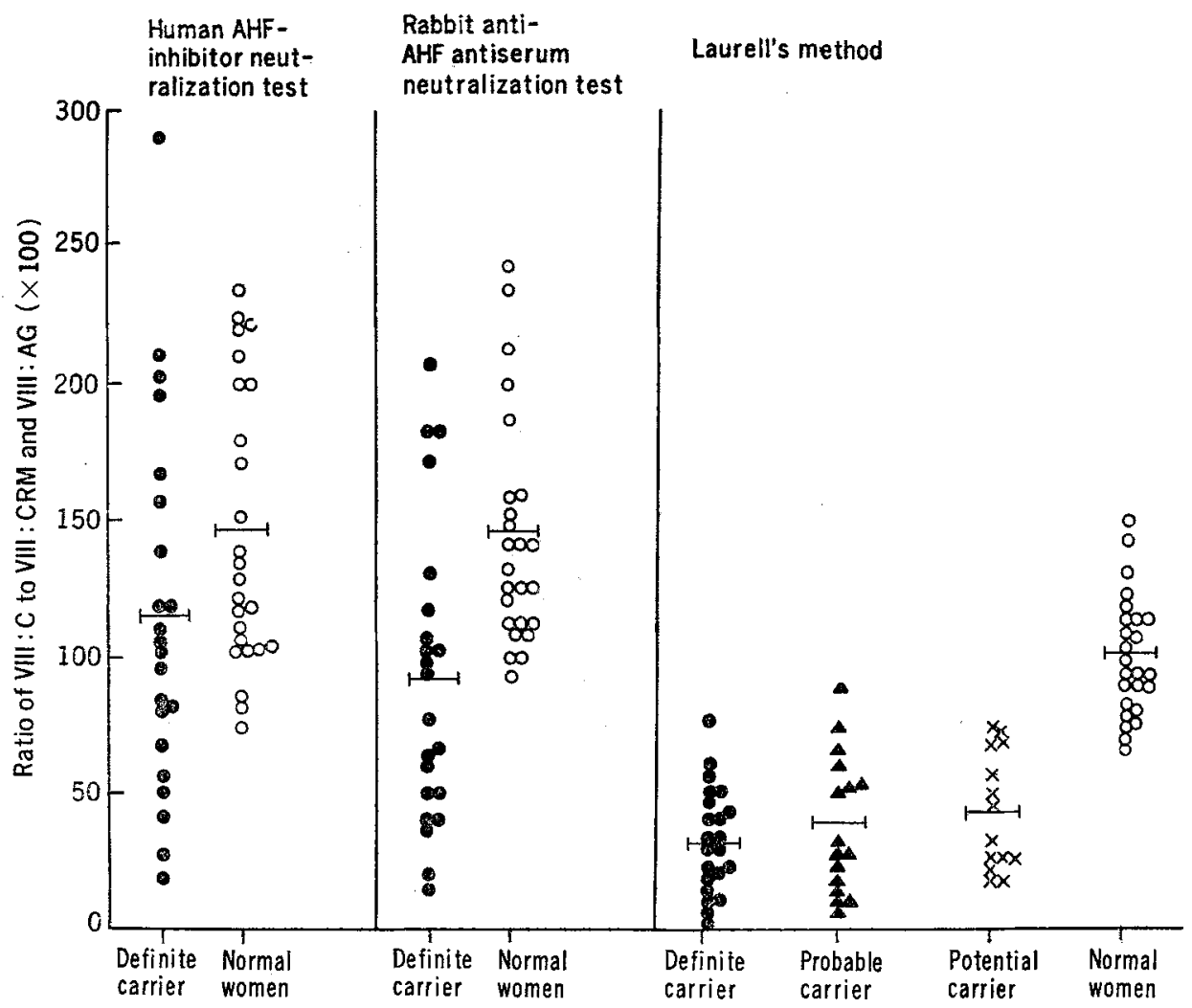

Fig. 2. The ratios of AHF procoagulant activity (VIII : C) to inhibitor-neutralization activity (VIII : CRMI), VIII : $\mathrm{C}$ to rabbit anti-AHF antiserum-neutralization activity (VIII : $\mathrm{CRM}_{\mathrm{R}}$ ), and VIII : $\mathrm{C}$ to AHF-like antigen (VIII : $\mathrm{AG}$ ) in normals and 3 groups of carriers. 


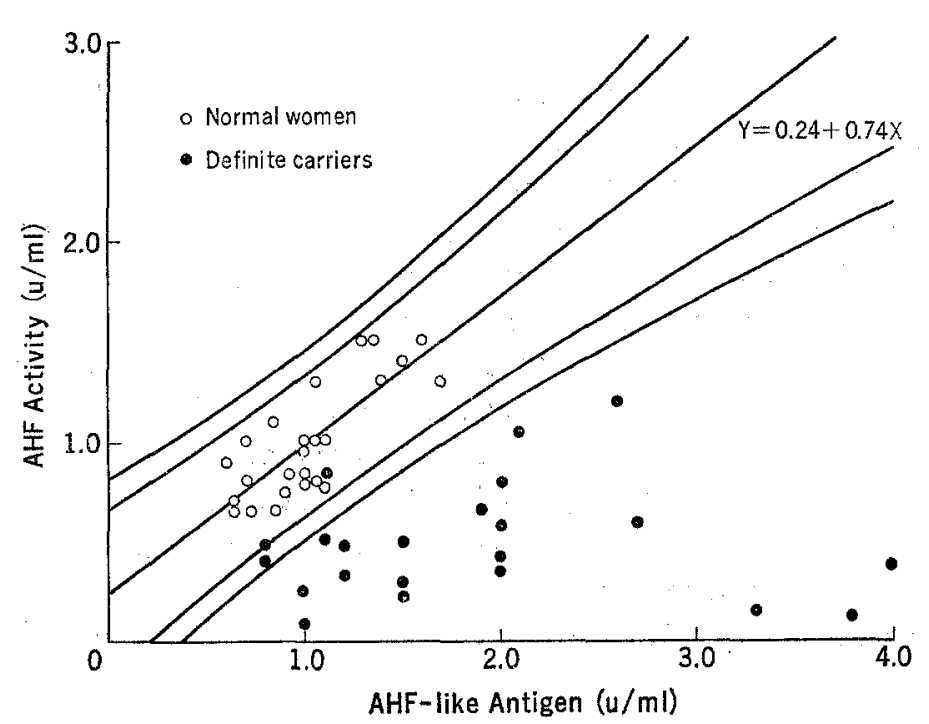

Fig. 3. The relationship of AHF activity to AHF-like antigen in definite carriers and normal women.

0.17 in definite carriers. The result of the three above ratios for normal women and carriers is plotted as a histogram in Fig. 2. Most of the definite carriers showed a "specific ratio" which was at least two standard deviations less than the normal mean. This indicates that the last method, the estimation of the ratio of VIII:C to VIII:AG, is of some value in detecting the carrier state.

The regression line relating VIII:C in plasma to VIII:AG in the same plasma in 25 normal women was calculated and the 95 and $99 \%$ confidence belts obtained for individual observations by the statistical method (Fig. 3). Figure 3 shows the relationship between VIII:C and VIII:AG in normal women and definite carriers. The center line is the regression line for the data obtained from normal women, the outermost lines represent the $99 \%$ confidence belt, and the other two lines represent the $95 \%$ confidence belt. The regression equation for normal women is $y=0.24+$ $0.74 \mathrm{x}$, where $\mathrm{y}$ is VIII $\mathrm{C}$ in units per milliliter, and $\mathrm{x}$ is the concentration of antigen in antigen units per milliliter. Nineteen of the $22(86 \%)$ and 20 of the $22(91 \%)$ definite carriers fell outside of the $99 \%$ and $95 \%$ confidence belts, respectively, while the determination of VIII:C alone detected the carrier state in 12 of the $22(54.5 \%)$. However, one out of the three definite carriers who did not fall outside of the $99 \%$ confidence belt could be distinguished on the basis of her VIII:C alone.

Application of this method to 16 probable carriers identified the carrier state in $11(69 \%)$ at the $99 \%$ confidence limit. And nine of the 14 potential carriers $(64 \%)$ were identified as carriers by this method. Figure 4 shows the relationship between of VIII:C and VIII:AG in probable and potential carriers. 


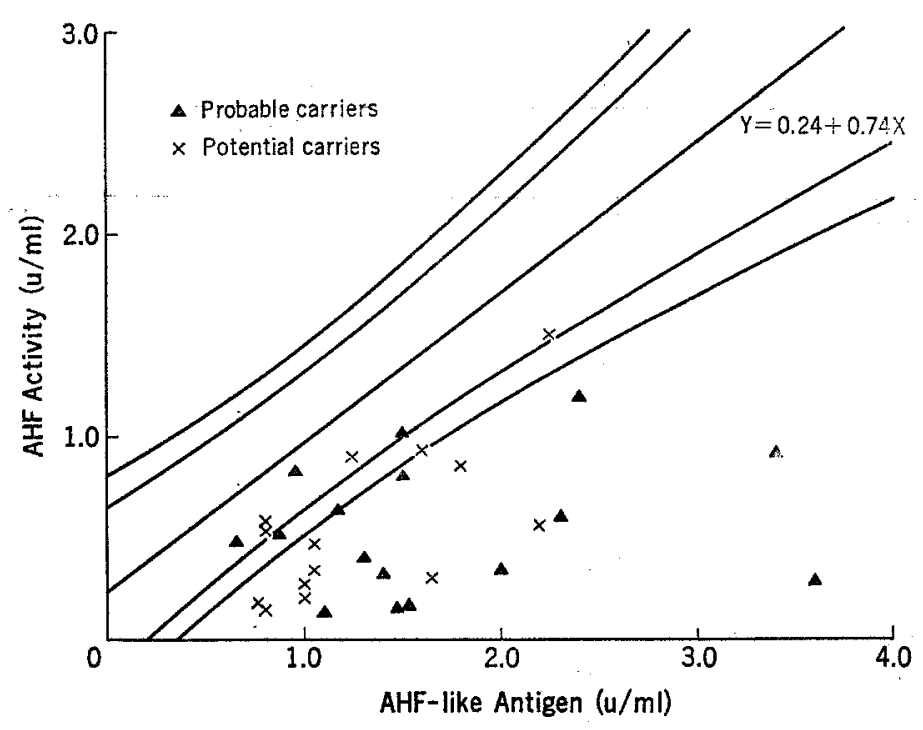

Fig. 4. The relationship of AHF activity to AHF-like antigen in probable and potential carriers.

\section{DISCUSSION}

Measurement of F.VIII activity alone is a poor way of identifying carriers of hemophilia, except in the $33-50 \%$ of them with VIII:C below $50 \%$ (Veltkamp et al., 1968; Ikari, 1969). No judgment can be made concerning the carrier state in women whose level of VIII:C is above $50 \%$.

Using the antibody-neutralizing method, Bennett and Huehns (1970) and Ekert et al. (1973) showed that the ratio of VIII:C to antibody-neutralization activity (VIII: $\mathrm{CRM}_{\mathrm{R}}$ ) was significantly lowered in the plasma of known carriers. The former reported that in six definite carriers there was approximately twice the amount of cross-reacting material than expected from their VIII:C. The latter results confirmed this. They used only heterologous (heteroimmune) antibody in antibody blocking technique. We have investigated the anibody-neutralization tests not only with rabbit anti-human AHF serum, but also with human inhibitor developed in a severe hemophiliac. But we could not establish the identification of hemophilia carriers by these antibody-neutralization tests.

On the other hand, using a quantitative immunoelectrophoresis technique, Zimmerman et al. (1971) and Bennett and Ratnoff (1973) reported that hemophilia carriers had higher than normal VIII:AG, and that application of "specific ratio," the ratio of VIII:C to VIII:AG by Laurell's method, provided positive identification of carriers. This specific ratio has been found to increase the score of carrier detection to over $90 \%$. In our study, 19 out of $22(86 \%)$ definite carriers could be detected 
Table 3. Studies of definite carriers of hemophilia A in different centers using the ratio of AHF procoagulant activity to AHF-like antigen as a discriminant.

\begin{tabular}{llcc}
\hline & & $\begin{array}{c}\text { Definite } \\
\text { carriers }\end{array}$ & $\begin{array}{c}\text { Identified } \\
\text { as carriers }\end{array}$ \\
\hline Zimmerman et al. & $(1971)$ & 25 & $23(92 \%)$ \\
Bennett \& Ratnoff & $(1973)$ & 42 & $40(95 \%)$ \\
Denson & $(1973)$ & 18 & $13(72 \%)$ \\
Prentice et al. & $(1974)$ & 25 & $19(76 \%)$ \\
Thomopoulos et al. & $(1975)$ & 18 & $17(94 \%)$ \\
Rizza et al. & $(1975)$ & 34 & $25(73 \%)$ \\
Bouma et al. & $(1975)$ & 22 & $18(82 \%)$ \\
Meyer et al. & $(1975)$ & 49 & $40(82 \%)$ \\
Gomperts et al. & $(1975)$ & 13 & $13(100 \%)$ \\
Kamiya et al. & $(1975)$ & 38 & $38(100 \%)$ \\
Hathaway et al. & $(1976)$ & 33 & $30(91 \%)$ \\
Okuda et al. & $(1976)$ & 20 & $19(95 \%)$ \\
Iizuka et al. & $(1976)$ & 16 & $15(95 \%)$ \\
Toraya et al. & $(1976)$ & 15 & $13(87 \%)$ \\
Ito et al. & $(1976)$ & 15 & $14(93 \%)$ \\
Author & $(1977)$ & 22 & $19(86 \%)$ \\
\hline
\end{tabular}

on the basis of specific ratio and 20 of $22(91 \%)$ if both VIII:C and specific ratio were taken into account. It is concluded that combined consideration of the level of VIII:C and the ratio of VIII:C to VIII:AG is most valuable method of detecting carriers of hemophilia A. Although the percentage of carriers detected is higher when the results of the ratio of VIII:C to VIII:AG are also taken into account, it is lower if compared with some previous reports (Table 3). Theoretically, these discrepancies could be related to technical differences in the assay of both VIII:C and VIII:AG, or to the use of antisera with slightly different specificity. Our present data are in agreement with those of Bouma et al. (1975), Meyer et al. (1975), and Toraya et al. (1976) who tested a large series of carriers. According to these authors, $10-30 \%$ of "hidden" definite carriers cannot be detected by present methods.

Despite improved means of treatment of patients with hemophilia A, genetic counseling constitutes an important aspect of the management of the patient and his family. Nowadays, in genetic counseling we can explain not only the consequent risks, but also offer a means of identifying female carriers on the basis of significantly low specific ratio.

In our studies, 11 of 16 probable carriers and 9 of 14 potential carriers were identifical as carriers at the $99 \%$ confidence limit. These results mean that sporadic cases were detected in 5 of the 16 families studied, and that 5 of the 14 potential carriers have about an $85 \%$ chance of being normal. Prentice et al. (1975) reported the distressing case of a female relative of a hemophiliac who was predicted to be normal after linear discriminant analysis, but who later gave birth to a hemophilic 
son. As they described, we feel that, before drawing definite conclusion from this new technique, these predictive tests must be validated in practice by seeing whether probable or potential carriers give birth to normal or hemophilic sons.

The results of this study were presented at the 20th Congress of The Japan Society of Human Genetics (Tokyo, Japan, 1975).

This research was supported in part by grants from the Ministry of Health and Welfare.

Acknowledgments. We wish to express our heartfelt thanks to Professor Emeritus K. Yoshida and Professor H. Fukui, Department of Pediatrics, Nara Medical University, for their kind and valuable advice. We are also indebted to Mr. O. Takamiya and Mr. K. Kawahara who cooperated in this study.

\section{REFERENCES}

Bennett, B. and Ratnoff, O.D. 1973. Detection of the carrier state for classic hemophilia. New. Engl. J. Med. 288: 342-345.

Bennett, E. and Huehns, E.R. 1970. Immunological differentiation of three types of hemophilia and identification of some female carriers. Lancet ii: 956-958.

Bloom, A.L., Davies, A.J. and Rees, S.K. 1966. A clinical and laboratory study of a patient with an unusual factor VIII inhibitor. Thromb. Diath. Haemorrh. 15: 12-28.

Bouma, B.N., van der Klaauw, Veltkamp, J.J., Starkenburg, A.E., van Tilburg and Hermans, J. 1975. Evalution of the detection rate of hemophilia carrier. Thrombo. Res. 7: 339-350.

Denson, K.W.E., Biggs, R., Haddon, M.E., Borrett, R. and Cobb, K. 1969. Two types of hemophilia ( $\mathrm{A}^{+}$and $\left.\mathrm{A}^{-}\right)$: A study of 48 cases. Brit. J. Haemat. 17: 163-171.

Denson, K.W.E. 1973. The detection of factor-VIII-like antigen in hemophilia carriers and in patients with raised levels of biologically active factor VIII. Brit. J. Haemat. 24: 451-461.

Ekert, H., Helliger, H. and Muntz, R.H. 1973. Detection of carriers of haemophilia. Thromb. Diath. Haemorrh. 30: 255-262.

Gomperts, E.D., Whitbread, P. and Feesey, M. 1975. Factor VIII-related antigen in the detection of the haemophilia carrier state. S. Afr. Med. J. 49: 1005-1007.

Hardisty, R.M. and Macpherson, J.C. 1962. A one-stage factor VIII (anti-haemophilic globlin) assay and its use on venous and capillary plasma. Thrombos. Diathes. haemorrh. 7: 215-229.

Hathaway, H.S., Lubs, M.L., Kimberling, W.J., and Hathaway, W.E. 1976. Carrier detection in classical hemophilia. Pediatrics 57: 251-254.

lizuka, A., Nagao, T. and Mimaya, J. 1976. Detection of carriers of classic hemophilia. Acta Haem. Jap. 39: 775.

Ikari, H. 1969. Factor VIII levels in carriers of hemophilia A. J. Nara Med. Ass. 20: 638-654.

Ito, M., Kobayashi, I., Takahashi, K., Sakuragawa, N. and Matsuoka, M. 1976. The detection of the carrier of hemophilia B. Acta Haem. Jap. 39: 776.

Kamiya, T., Ishiguro, J., Koie, K. and Saito, H. 1975. Symposium on the blood coagulation and fibrinolysis. (6) Immunological studies on hemophilia A, carriers of hemophilia A and von Willebrand's disease. J. Jap. Soc. Int. Med. 64: 1121-1126.

Laurell, C.B. 1966. Quantitative estimation of proteins by electrophoresis in agarose gel containing antibodies. Analyt. Biochem. 15: 45-52.

Mersky, C. and Macfarlane, R.G. 1951. The female carriers of hemophilia A. Clinical and laboratory study. Lancet $260 ; 487-490$. 
Meyer, D., Plas, A., Allain, J.P., Sitar, G.M. and Larrieu, M.J. 1975. Problems in the detection of carriers of haemophilia A. J. Clin. Path. 28: 690-695.

Okuda, T., Mikami, S., Fukui, H. and Yoshida, K. 1976. Detection of carrier of hemophilia A. Acta Haem. Jap. 39: 774.

Prentice, C.R.M., Forbes, C.D., Morrice, S. and McLaren, A.D. 1975. Calculation of predictive odds for possible carriers of haemophilia. Thromb. Diath. Haemorrh. 34: 740-747.

Rapaport, S.I., Patch, M.J. and Moore, F.J. 1960. Antihaemophilic globulin levels in carriers of haemophilia. J. Clin. Invest. $39: 1619-1625$.

Rizza, C.R., Rhymes, I.L., Austen, D.E.G., Kernoff, P.B.A. and Aroni, S.A. 1975. Detection of carriers of haemophilia: a 'blind' study. Brit. J. Haemat. 30: 447-456.

Thomopoulos, D., Scliros, P. and Lyberatos, C. 1975. Detection of carriers of haemophilia A. Acta Haemat. 54: 32-35.

Toraya, A., Meguro, T., Ishii, K. and Yamada, K. 1976. Studies on Laurell's method for detection of carrier of hemophilia A. Acta Haem. Jap. 39: 775.

Veltkamp, J.J., Drion, E.F. and Loeliger, E.A. 1968. Detection of the carrier state in hereditary coagulation disorders. II. Thrombos. Diathes. haemorrh. 19: 403-422.

Zimmerman, T., Ratnoff, O.D. and Littell, A.S. 1971. Detection of carriers of classic hemophilia using an immunologic assays for antihemophilic factor (Factor VIII). J. Clin. Invest. 50: 255258. 